\title{
Strategies for Reducing Dental Stress in Children
}

\author{
Mohammed Karimi* \\ Department of Pediatric Dentistry, Sepideh Dental Clinic, Iran
}

Received: 韭 August 30, 2018; Published: 非 September 06, 2018

*Corresponding author: Mohammed Karimi, Department of Pediatric Dentistry, Sepideh Dental Clinic, Iran

\section{Opinion}

The dental office for children has always been scary and eerie. The reason for this fear is the lack of mental fitness of children towards the dental health environment. Unknown instruments, scary sounds of dental devices, and sometimes seeing others' fears during dental procedures would affect the child's mind; and creates fear within them. No research has pointed to the definitive causes of anxiety and stress, but some studies have shown that the bad experience of dental treatments associated with pain is one of the most common in this case. Other factors include the possibility of pain during a procedure, anesthetic ineffectiveness, sterile odor in the office or clinic, lack of comfort and the voice of the dental drill. Children are divided into five groups in terms of behavior in the dental environment. For some patients, anxiety and stress may be related to the way a clinic staff has treated them [1]. For example, they may have felt that the dentist or his assistant did not have enough time to answer their questions or did not try to resolve their concerns; or even the patient might have spent one full day of treatment at the clinic or in a stressful environment. This may not seem to be a big problem, but the anxiety of dentistry can cause patients negligent to periodic oral care and dental treatments. Furthermore, with no timely referrals, these small issues can lead to too many problems. Worse, it might require considering more serious and possibly more unpleasant treatments.

\section{Children's Behavioral Division in Dentistry}

Children's behavior in the dental environment is not the same and the dentist can use different methods for dental work according to the psychological diagnosis of the child. In terms of dental treatment, children are divided into 7 groups of behavioral [2].

\section{Fully Cooperative Child}

This group is those children who have spirit of cooperation and have the minimum of anxiety. They can be easily treated when guidance is given to them on how the dentist will treat their teeth in a prescribed framework. This group of children is very curious to know how any dental instruments work [3]. They always have questions that refresh their minds, which need to be answered by the dentist. In most cases, especially during the second session, when their anxiety has decreased, they are so brave that will go to the treatment room without accompanying by their parents. There are no specific restrictions on this group. The average age of this group of children is between 4 and 8 years of age.

\section{Child with Controlled Behavior}

In this case we face small patients who are about 3-6 years old. This behavior occurs with signs of crying, screaming, and kicking on the floor in front of the reception desk, waiting room, or even before entering the office. Their reaction is a kind of tantrum [4]. Their behavior is due to acute anxiety or fear of the dental environment. Children, who are reluctant to accept treatment show irritability, distemper and withdrawal, but these behaviors are not severe. It is necessary to establish a communication path with these patients. The baby should go urgently out of the waiting room and leave the rest of the patients so that the anxiety does not penetrate and transfer to the rest of the children. Parents must calm down the unhappy and frustrated child [5]. To win the trust of such children, it is advisable to do only oral examination in the first session. Or, if the child is inclined, the dentist will apply his professional tricks for fluoride therapy. Finally, giving a prize can bring the patient home. This will provide a preliminary basis for the next dental services.

\section{A Child with Indifferent and Daring Behavior}

This behavior may be seen in all age groups, but it is particularly noticeable in children of primary school age. This behavior is also largely controllable. This type of children most often repeats the sentences such as" I do not want" or "I don't like". These are stubborn and spoiled children. A firm and decisive approach, with clear instructions, changes their behavior [6]. These children usually not only do not open their mouths on the dental chair, but also refuse to talk and co-operate. Because they are often brought to the office by force, they feel their freedom and respect might be violated. With such children, we do not start with the use of force. If the child expresses dissatisfaction with the dental treatment, we should also be agreeing with him that although these actions are not pleasant, but it is necessary for him. While we are honest with them, we should start discussing oral hygiene, toothbrushes, etc., so that we can gradually establish enough communication with the child [7]. 


\section{Shy Child}

Shyness is less of a negative form, and if dentist does not behave appropriately with this group of children, their reactions become worse and become uncontrollable. These children are usually hidings behind their parents at the time they arrive and are not separated from their parents. When we walk towards them, some start moving back. Some others might be in hesitant mode or start to cry; or even sometimes cover their eyes with their own hands to hide their fears. Their cry is more like whine. This category of children is strongly supported by parents [8]. Excessive attention and respect for these children also causes the child to become shy. It's better to give confidence to these children and guide them. After several sessions, these children become more positive and cooperative, so that the next session does not require parental support.

\section{Group Under Pressure but Cooperative}

This group of children is on the border line of positive and negative cooperation. They accept the treatment but take precautionary dental orders [9]. At the same time, they are not pleased with these acts, and when they speak, their voice shakes. Sometimes this tremor spreads to his body and this thrill precludes the child from co-operating. Providing a happy and stressfree environment for these children, they will become a part of cooperative patients.

\section{The Crying Group}

Children who are severely afraid and cry; they have severe avoidance behaviors; and prevent the treatment. This group includes children with a bitter experience of dentistry. Crying is the specific reaction to the sound of the turbine. Excited kid sounds are stable. Despite local anesthetics, they complain about pain. They are afraid of the sound of the machine. When the turbine works and has a contact with tooth, they scream loud and show resistance. Sometimes, they may show a sudden movement when turbine touches their teeth. The treatment of this group requires patience and toleration. Sometimes, parents begin to interfere with the dental work when they see crying child. They often comment that the teeth might not have adequate numbness [10]. It should be mentioned to these parents that the dentist will not start dental work until he observes symptoms of numbness in the child. In addition, the dentist should give assurance this crying is not due to child is having pain, but the child only uses this remedy to prevent dentist from working.

\section{Non-Cooperative Group}

People in this category are children who have certain weaknesses or are mentally retarded which are prescribed special behavioral control techniques. Another group in this category is very small children who cannot communicate with them through dialogue [11]. In fact, these children are unable to cooperate because of their age. Working with this group is very difficult, overwhelming and exhausting. Their treatment should be done only with complete anesthesia in the hospital environment. For such individuals especially in toddlers, restraining and using force is not a wise approach. The application of this method creates a crisis called "bitter experience of dentistry". Hence, that very young child becomes a totally non-cooperative one in any dental work.

\section{What can be Done as A Dentist to Reduce Child Anxiety?}

The first step in this direction is to understand the causes of stress in pediatric patients. Children are very sensitive. They are very quickly affected by environmental factors, which can unfortunately affect the process of dental procedures. The dental environment and its surroundings are one of the important factors that a child should have a comfortable and relaxed feeling. Here, we can identify these environmental factors and refer to a series of useful strategies to reduce stress and anxiety in these children. Changes in the design or the environment of the clinic can help reduce the stress [12]. This can diminish the feeling of anxiety, frustration, confusion, embarrassment, helplessness or fear before a dental procedure is performed in patients.

\section{Scent of the Environment}

There is often a specific odor in the hospitals, clinics and other sterilized spaces, which causes an emotional response in many patients. With application of relaxing fragrances such as lavender (from the family of lindenum) and oranges in the clinic and waiting rooms, help to relax patients before treatment.

\section{Appearance of Environment}

Use relaxing colors like blue and green on the walls, chairs and furniture. These colors can help create a more comfortable environment for patients. Also, undecorated walls can cause anxiety in people, so the good idea is to add decorations like beautiful artwork and beautiful décor.

\section{Sounds}

One of the most common causes of stress in patients is dental drill sound. So, to reduce the noise of dental equipment, you can place compressors and other noisy equipment in a separate area and create a relaxing environment with gentle light and music playback.

\section{Light}

Dental clinics require a bright environment to perform dental works but bright and direct light on the patient's face can trigger stress and anxiety. Set the status of the lamp so that it would shine in patient's mouth instead of his eyes try to reduce the backlight in the clinic.

\section{Comfort}

The furniture of the waiting room and the dental chair should be clean and comfortable. Additionally, setting the ambient 
temperature at lower levels may help reduce stress and anxiety. If the environment is warm, the child may show combinations of restlessness, irritability, distemper, discomfort and fussing. If the patient appears to be distressed and anxious, give him a small blanket to lie down on the sofa.

\section{Other Techniques}

In addition to the office environment or clinic surroundings, some other useful measures to reduce the anxiety of children include:

\section{Communication}

Maintaining a clear communication with children from the time of booking appointments and even after treatment can help reduce their stress. Before starting any procedure, talk about what is going to happen in a childish language. Avoid using some words like blood, anesthetic needle and pain. Answer their questions promptly; and follow up their conditions during and after recovery.

\section{Control}

Children naturally feel more comfortable if they feel they are under controlled conditions. Before starting treatment, it is best to identify a certain number of marks between the child and the dentist, for example, lifting one hand when they need to rest during the treatment. Ask their opinions about the movies and music they are playing for them. Show them a movie they want to watch so that their attentions get focused on the movie during the treatment and distracted from the dental procedures. Adding a TV screen, aquarium and other interesting elements in the clinic's waiting room helps patients focus on something else.

\section{Care and Attention}

This are one of the easiest ways to reduce the patient's discomfort, indicating a desire for extraordinary effort to care for the patient. For example, giving an ice cream to children whose teeth have been extracted, or even offering medications for those who have pain, shows caring. In other words, it indicates the tendency of the dentist to comfort his patients [13-15].

Patients, who are waiting for hours to complete their treatment, are likely to be more anxious and stressful. Therefore, it is imperative that the medical staff ensure that they can control and reduce the stressful conditions as well. For instances, this can be done by providing patients with cold or hot drinks. The important thing is that the staff should handle the patients with a smile, kindness and respect for the patients. To conclude and complete this review, this final detail should be added. Despite the advancement of technology in painless dentistry, patients' anxiety and stress continues to be an important concern in dentistry. Many people feel pain when they see, smell and hear voices in a dental clinic; or even reminding them. Beyond that, hidden fear of dental procedures (dental phobia) and anxiety can affect the patient's commitment to dental care and proper care of her teeth. There are a few environmental factors that their defects and weakness can exacerbate stress in children. These include clinic environment, the smell of dental materials, staff's behavior and lack of safety and comfort. In terms of behavioral dentistry, children are divided into 7 groups [16]. According to these behaviors, professional tricks should be used in dental treatment to facilitate dentist's work. By applying a series of strategies, an expert and skilled dentist can reduce stress in children and successfully complete the treatment.

\section{References}

1. Eli I (1992) Oral psychophysiology: stress, pain and behavior in dental care. Florida: CRC Press.

2. Eli I, Uziel N, Bath R, Kleinhauz M (1997) Antecedents of dental anxiety: learned responses versus personality traits. Community Dent Oral Epidemiol 25(3): 233-237.

3. Freeman RE (1985) Dental anxiety: a multifactorial aetiology. Br Dent J 159(12): 406-408.

4. Milgrom P, Weinstein P, Getz T (1995) Treating fearful dental patients. ( $2^{\text {nd }}$ edn). University of Washington in Seattle, Washington, USA.

5. Newton JT, Baghaienaini F, Goodwin SR, Invest J, Lubbock M, et al. Stress in dental school.

6. Klingberg G, Berggren U, Carlsson SG, Noren JG (1995) Child dental fear: cause-related factors and clinical effects. Eur J Oral Sci 103(6): 405-412.

7. Bourne EJ (2006) The anxiety and phobia workbook ( $4^{\text {th }}$ edn) Oakland, CA: New Harbinger Publications 4-29.

8. Klingberg G, Broberg AG (2007) Dental fear/anxiety and dental behavior management problems in children and adolescents: a review of prevalence and concomitant psychological factors. Int J Paediatr Dent 17(6): 391-406.

9. Holst A, Schroder U, Ek L, Hallonsten AL, Crossner CG (1988) Prediction of behavior management problems in children. Scand J Dental Res 96(5): 457-465.

10. Wright GZ, Alpern GD, Leake JL (1973) A cross validation of variables affecting children's cooperative behavior. J Can Dent Assoc 39(4): 268273.

11. Hoist A, Crossner CG (1984) Management of dental behavior problems. A 5-year follow-up. Swed Dent J 8: 243-249.

12. Hoist A, Crossner CG (1987) Direct ratings of acceptance of denial treatment in Swedish children. Community Dent Oral Epidemiol 15: 258-263.

13. Hoist A, Ek L (1988) Effect of systematized "behavior shaping" on acceptance of dental treatment in children. Community Dent Oral Epidemiology 16(6): 349-355.

14. Corah NL, Oshea RM, Bissell GD (1985) The dentist- patient relationship: perceptions by patients of dentist behavior in relation to satisfaction and anxiety. J Am Dent Assoc 111(3): 443-436.

15. Hicham Riba, Saleha Al Zahrani, N Al Buqmi, AA Jundi (2017) A Review of Behavior Evaluation Scales in Pediatric Dentistry and Suggested Modification to the Frankl Scale. EC Dental Science 16(6): 269-275.

16. Shetty R, M Khandelwal, S Rath (2015) RMS Pictorial Scale (RMS-PS): An innovative scale for the assessment of child's dental anxiety. Journal of Indian Society of Pedodontics and Preventive Dentistry 33(1): 48-52. 


\section{(C) \\ This work is licensed under Creative Commons Attribution 4.0 License}

To Submit Your Article Click Here:

Submit Article

DOI: 10.32474/IPDOAJ.2018.02.000126

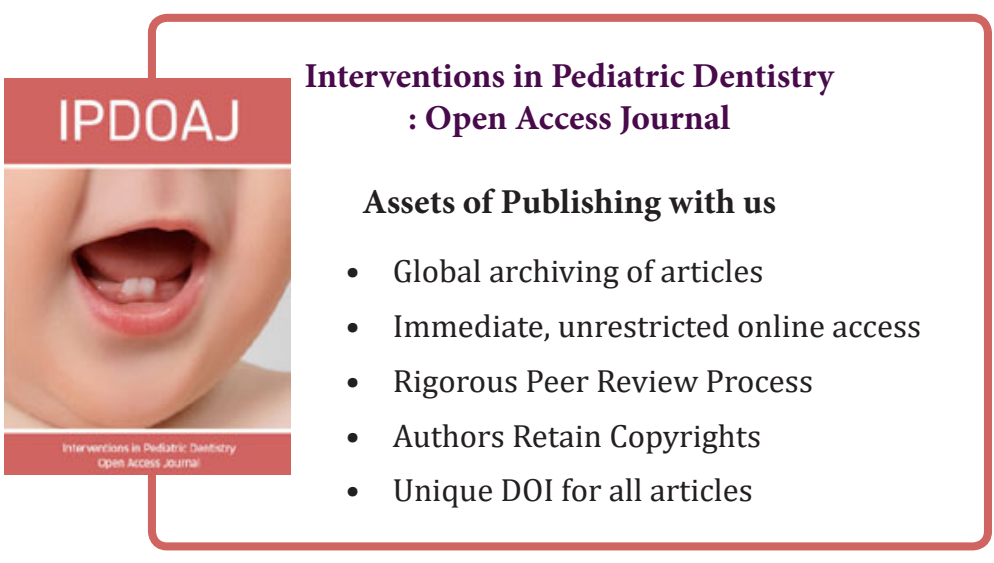

